\title{
Experience with sorafenib in the treatment of advanced renal cell carcinoma
}

\author{
Giuseppe Procopio, Elena Verzoni, Isabella Testa, Nicola Nicolai, \\ Roberto Salvioni and Filippo DeBraud
}

\begin{abstract}
The molecular-targeted agent sorafenib is the first anticancer agent able to slow the progression of advanced/metastatic renal cell carcinoma, a tumor that was formerly refractory to conventional therapy. Experience from everyday clinical practice and investigations exploring the suitability of this agent for patients with harmful pathological conditions has extended the use of sorafenib to other settings of renal cell carcinoma and to particular risk populations. The aim of this review is to provide evidence on the most effective and safe use of sorafenib. The review pays particular attention to patients who have several comorbidities, such as impaired renal and cardiac function, and older patients whose frailty due to impaired organ function necessitates the most careful administration of targeted antineoplastic agents.
\end{abstract}

Keywords: First-line treatment, older people, renal cell carcinoma, sorafenib, targeted therapies

\section{Introduction}

Seven years ago, the introduction of the moleculartargeted agent sorafenib was a breakthrough in oncologic therapy and a fundamental step forward in the treatment of advanced/metastatic renal cell carcinoma (mRCC). Sorafenib has led to disease control or progression slowdown in a consistent patient population formerly resistant to almost all available therapeutic approaches, such as chemotherapy and radiotherapy, and in a minority sensitive to cytokines [Escudier, 2011]. Since the introduction of sorafenib, several other targeted agents for the treatment of mRCC have been introduced into clinical practice. However, phase III randomized studies have not identified which drug confers the most benefit and which patient population benefits most, so physicians have moved from lacking any therapeutic means to questioning which one of several might be the best. The extensive use of sorafenib in clinical trials and clinical practice has generated a large amount of data that provided detailed information on the activity and safety of this drug, even in highly dissimilar patient populations with varying treatments.

The aim of this review is to weigh the current evidence concerning therapy with sorafenib in patients with mRCC, particularly focusing on frontline treatment in selected patient populations, sequential therapy with similar molecules, and use in patients with particular clinical profiles.

\section{General overview of sorafenib characteristics}

Based on the results of phase III randomized studies, US and European regulatory authorities approved sorafenib as the first oral multikinase inhibitor for the treatment of mRCC [Escudier, 2011]. Sorafenib is a dual-action, multitarget, tyrosine kinase inhibitor directed against several kinase receptors involved in tumor cell proliferation and tumor angiogenesis, such as Raf kinases, vascular endothelial growth factor receptor 2 , vascular endothelial growth factor receptor 3, plateletderived growth factor receptor $\beta$, c-KIT, and FLT-3 [Wilhelm et al. 2006, 2008].

\section{Phase I}

The efficacy and safety of sorafenib have been initially evaluated in a series of phase I studies that tested different dose levels in patients with advanced and refractory solid tumors [Awada et al. 2012; Clark et al. 2005; Moore et al. 2005;
Ther Adv Urol

(2012) 4(6) 303-313

DOI: $10.1177 /$

1756287212457216

(c) The Author(s), 2012. Reprints and permissions: http://www.sagepub.co.uk/ journalsPermissions.nav
Correspondence to: Giuseppe Procopio, MD Department of Medical Oncology, Fondazione IRCCS, Istituto Nazionale dei Tumori, Via G. Venezian, Milan 1-20133, Italy giuseppe.procopiod istitutotumori.mi.it Elena Verzoni, MD Isabella Testa, MD Nicola Nicolai, MD Roberto Salvioni, MD Filippo DeBraud, MD Department of Medical Oncology, Fondazione IRCCS, Istituto Nazionale dei Tumori, Milan, Italy 
Strumberg et al. 2005]. In all studies, sorafenib was well tolerated when administered twice daily at doses up to $400 \mathrm{mg}$, generally displaying mild to moderate and manageable toxicity. In addition, the drug showed a substantial antitumor activity chiefly characterized by disease stabilization and tumor shrinkage [Awada et al. 2012; Clark et al. 2005; Moore et al. 2005; Strumberg et al. 2005].

\section{Phase II}

The first pivotal phase II study was undertaken as a randomized discontinuation trial, a study design considered innovative at the time [Ratain et al. 2006]. In the space of 12 weeks (run-in phase), 202 patients with mRCC received $400 \mathrm{mg}$ of sorafenib twice daily. At the end of this period, patients showing tumor burden reductions of at least $25 \%(n=73 ; 36 \%)$ continued treatment with sorafenib, whereas patients with progressive disease or increased tumor burden of $25 \%$ or more $(n=51 ; 25 \%)$ discontinued the study. The remaining patients with stable disease (fluctuations of tumor size of $25 \%$ or more compared with baseline), who were still potentially considered to be responders $(n=69 ; 34 \%)$, were randomized to receive either sorafenib or placebo for another 12 weeks. The primary endpoint of the study was the percentage of patients who were progression free 12 weeks after randomization. At that time, $50 \%$ (16 of 32) of the patients treated with sorafenib and $18 \%$ ( 6 of 33 ) of the patients in the placebo group were progression free $(p=0.007)$. Median progression-free survival (PFS), a secondary endpoint, was 24 weeks in the sorafenib group and 6 weeks in the placebo group $(p=0.0087)$ [Ratain et al. 2006].

\section{Phase III}

The international pivotal randomized, placebocontrolled phase III study (Treatment Approaches in Renal Cell Cancer Global Evaluation Trial TARGET) accrued 903 patients with inoperable mRCC from 117 oncology institutions throughout 19 countries [Escudier et al. 2007a]. Selection criteria included patients progressing after firstline treatment with cytokines [interferon or interleukin-2 (IL-2)] or conventional chemotherapy with a life expectancy of at least 12 weeks, Eastern Cooperative Oncology Group (ECOG) performance status $0-1$, and low or medium Memorial Sloan-Kettering Cancer Center prognostic risk factors. Patients were randomly allocated to treatment with sorafenib at a dose of $400 \mathrm{mg}$ twice daily $(n=451)$ or placebo $(n=452)$, which was orally administered continuously until disease progression, unacceptable toxicity, or patient's consent withdrawal. The primary endpoint of the study was overall survival (OS); the secondary endpoints were PFS and disease control rate [Escudier et al. 2007a].

A preplanned interim analysis carried out as soon as 363 patients had progressed showed a statistically significant advantage in terms of median PFS for sorafenib (5.5 months) compared with placebo (2.8 months) [hazard ratio (HR) $0.44 ; 95 \%$ confidence interval (CI) $0.35-0.55$; $p<0.000001$ ], with a $56 \%$ progression risk reduction. In light of this evidence, a protocol amendment by the regulatory authorities for ethical principles was applied; blindness suppression allowed patients in the placebo group to benefit from active treatment with sorafenib (crossover) [Escudier et al. 2007a].

\section{Overall survival}

The first preplanned survival analysis was carried out immediately after $48 \%$ of patients initially randomized to treatment with placebo were shifted to treatment with sorafenib [Escudier et al. 2009a]. At that time, 220 deaths were recorded: 97 deaths $(22 \%)$ in the sorafenib group and 123 deaths $(27 \%)$ in the placebo group. Treatment with sorafenib was distinguished by an improvement in OS (HR 0.71; 95\% CI 0.54-0.94; $p=0.015$ ). Six months after the crossover, the total number of deaths was 367: 171 deaths in the sorafenib group and 196 deaths in the group initially assigned to placebo. Median OS was 19.3 and 15.9 months for the two groups, respectively, with a statistically significant advantage in favor of sorafenib (HR 0.77 ; 95\% CI 0.63-0.95; $p=0.02$ ); nevertheless, this result did not fulfill the predefined significance limits fixed by the study (O'Brien-Fleming threshold for statistical significance: $p=0.0094$ ) [Escudier et al. 2009a].

At the final analysis, the total number of deaths was 561: 278 deaths in the sorafenib group and 283 deaths in the group initially assigned to placebo, with median survival of 17.8 and 15.2 months, respectively (HR 0.88; 95\% CI $0.741-1.04$; $p=0.146)$. It clearly follows that the protocol amendment set for ethical reasons negated the possibility of a true and clear-cut evaluation of survival in the study, which was severely biased by the confounding effects due to the shift of 
patients initially randomized to treatment with placebo to treatment with the active drug. However, if these patients are excluded from the analysis, sorafenib is found to induce a statistically significant benefit in terms of survival compared with placebo [Escudier et al. 2009a]. In addition, sorafenib yielded a good objective response chiefly characterized by a prevalence of stable disease; disease control was seen in $80 \%$ of treated patients. The patients tolerated the drug well; mild to moderate and manageable adverse effects chiefly consisted of skin reactions, gastrointestinal disturbances, and cardiovascular effects, of which hypertension was the most frequent and severe [Escudier et al. 2009a].

\section{Sorafenib in everyday clinical practice}

To collect data on the characteristics and role of the drug in clinical practice, the efficacy and safety of sorafenib have been evaluated in two large expanded-access studies, in North America (North American Advanced Renal Cell Carcinoma Sorafenib Study - NA-ARCCS) and Europe (European Advanced Renal Cell Carcinoma Sorafenib Study - EU-ARCCS), on a total of 3500 patients with mRCC [Beck et al. 2011; Stadler et al. 2010]. A third, recently concluded study in Europe, the Asia-Pacific area, and Latin America (Patient Characteristics in Renal Cell Carcinoma and Daily Practice Treatment with Sorafenib - PREDICT) supplied additional information on the efficacy and safety of sorafenib [Jäger, 2012].

In the EU-ARCCS, which was carried out in 11 European countries, sorafenib was administered to 1145 patients with $\mathrm{mRCC}$ who relapsed after previous systemic treatment with cytokines or other targeted agents or with mRCC that from the beginning was not amenable to any other treatment [Beck et al. 2011]. Baseline inclusion criteria required ECOG performance status $0-2$ and life expectancy of at least 2 months; following a protocol amendment, patients with asymptomatic brain metastases were also included [Beck et al. 2011]. Continuous twice-daily $400 \mathrm{mg}$ doses of sorafenib were administered until disease progression or unacceptable toxicity occurred. The endpoints of the study were safety, PFS, and disease control rate. The results are completely in line with those of the TARGET study: PFS was 6.6 months (95\% CI 6.1-7.4); stable disease was observed in most patients (86\%), with only $4 \%$ partial or complete responses, while $10 \%$ had disease progression. The safety profile was similar to that recorded in the developmental or registration studies [Beck et al. 2011].

The inclusion criteria of the NA-ARCCS, which were less strict than those of the TARGET phase III pivotal study, allowed the accrual of 2504 patients. Among these patients, different subgroups were identified, such as older patients, patients with non-clear-cell histology $(n=202)$, and patients with active brain metastases or in progression, previously treated $(n=1255)$ or not previously treated $(n=1247)$ with systemic therapy. The efficacy and safety analysis was carried out on the whole sample and on different subgroups. When sorafenib was marketed in the United States 6 months after the beginning of the study, the expanded-access program was closed, and the 328 patients who had non-clear-cell histology or who had been treatment naive until they were accrued were shifted to another open study for another 6 months of treatment. Therefore, for the remaining patients representing most of the sample, the median duration of treatment was limited to only 12 weeks (range $<1-81$ weeks). Consequently, the value of PFS in this study is not comparable to the PFS values recorded in other studies with stricter methodology [Stadler et al. 2010]. Despite this limitation, among 1891 patients evaluated for response, stable disease was observed in $80 \%(n=1891)$, and partial response was observed in $4 \%(n=67)$. In the subgroups identified as previously treated with cytokines or not previously treated with cytokines, as well as in other subgroups, efficacy and safety data were similar to those in the TARGET study. This finding confirms the antitumor activity and good safety profile of sorafenib in a more heterogeneous patient population than the selected population included in the pivotal phase III study [Stadler et al. 2010].

The PREDICT study, carried out in 592 centers throughout 18 countries, allowed further evaluation of the efficacy and safety of sorafenib in everyday clinical practice [Jäger, 2012]. The main endpoint of the study was tumor status evaluation after approximately $3,6,9$, and 12 months [ClinicalTrials.gov identifier: NCT00895674]. Other endpoints were treatment duration, safety, PFS, metastatic progression, and performance status deterioration. All endpoints were assessed at 3, 6, 9, and 12 months after the initiation of treatment. Data on patients showing characteristics considered criteria for exclusion in other 
Table 1. Sorafenib first-line data are reported. The range of progression-free survival benefit fluctuates between 5.7 and 9.2 months.

\begin{tabular}{lcll}
\hline Study & Patients $(n)$ & PFS (months) & DCR (\%) (CR + PR + SD) \\
\hline General first-line patients & & & \\
Gollob et al. [2006] & 32 & 9.2 & 75 \\
Jonasch et al. [2009] & 40 & 7.4 & 73 \\
Escudier et al. [2009b] & 97 & 5.7 & 79 \\
Stadler et al. [2010] & 220 & 8.1 & 83 \\
Rini et al. [2011b] & 51 & 9.0 & 85 \\
Aveo-Astellas (2011) & 181 & 9.1 & 24 \\
Procopio et al. [2011a] & 62 & 6.9 & 74 \\
Patients unsuitable for cytokines & & 91 \\
Bellmunt et al. [2010b] & 26 & 7.5 & 71 \\
Beck et al. [2011] & 281 & 6.2 & \\
\hline CR, complete response, DCR, disease control rate; EU-ARCCS, European Advanced Renal Cell Carcinoma Sorafenib \\
Study; NA-ARCCS, North American Advanced Renal Cell Carcinoma Sorafenib Study; PFS, progression-free survival; \\
PR, partial response; SD, stable disease.
\end{tabular}

studies were accrued. The available data showed that full-dose administration of $400 \mathrm{mg}$ of sorafenib twice daily was achieved in most patients $(91 \%)$, and treatment lasted 12 months or even longer for approximately $25 \%$ of these patients. The treatment was well tolerated; adverse effects included hand-foot skin reaction $(20 \%)$, diarrhea $(17 \%)$, rash $(9 \%)$, alopecia $(6 \%)$, hypertension $(4 \%)$, and fatigue $(3 \%)$. Treatmentrelated adverse effects have been documented in less than $5 \%$ of patients [Jäger, 2012].

\section{Frontline treatment}

Based on the evidence submitted, the US Food and Drug Administration (FDA) approved sorafenib for the treatment of all patients with mRCC, whether or not they were treatment naïve [US Food and Drug Administration, 2007]. In contrast, the European regulatory authorities approved the drug for patients who relapsed after treatment with cytokines, allowing front-line treatment only to patients considered unsuitable for such therapy [European Medicines Agency, 2006]. However, because the number of patients who are intolerant of, or potentially ineligible for, immunotherapy is somewhat large [Zustovich et al. 2011], the role of sorafenib as a frontline treatment became more and more extended in clinical practice.

In addition to the speculation previously mentioned, experimental evidence supports the role of sorafenib in the frontline setting [Bellmunt et al. 2010a; Escudier et al. 2012; Kirchner et al. 2010; Zustovich et al. 2011]. Following the disappointing results of the early phases of the drug's development in a head-to-head study comparing sorafenib and interferon, which showed no differences between the two drugs, especially in terms of PFS [Escudier et al. 2009b, 2012], a series of subsequent investigations have contradicted this initial finding (Table 1). In two recent comparative studies conducted during the development of two new targeted agents (AMG386 and tivozanib), sorafenib was the reference drug in the frontline treatment: in both studies, PFS with sorafenib was definitely higher than that initially reported and was in line with that observed for the competitors [Aveo-Astellas, 2011; Rini et al. 2011b]. As a result, the guidelines of the most reliable international scientific organizations and scientific societies have acknowledged the role of sorafenib as a frontline treatment in different types of mRCC and different patient populations. The National Comprehensive Cancer Network guidelines authorize the use of sorafenib for selected patients with mRCC, particularly patients with clearcell-prevalent histology [National Comprehensive Cancer Network, 2012]. European Organisation for Research and Treatment of Cancer guidelines [De Reijke et al. 2009] consider the use of sorafenib (level of evidence 2A) for individual patients at risk of cardiac toxicity and older patients. An International Society of Geriatric Oncology position paper [Bellmunt et al. 2009], emphasizing the 
Table 2. A summary of studies on use of sorafenib in sequential therapy.

\begin{tabular}{|c|c|c|c|c|c|c|}
\hline Sequence & $\begin{array}{l}\text { No. of } \\
\text { studies* }\end{array}$ & Phase III & Phase II & EAP & Retrospective & Total patients \\
\hline \multicolumn{7}{|c|}{ Sorafenib $\rightarrow$ TKI } \\
\hline Sun $\rightarrow$ Sor & 18 & 1 & 4 & 1 & 12 & 820 \\
\hline Sor $\rightarrow$ Sun & 14 & & & & 14 & 674 \\
\hline Sor $\rightarrow$ Ax & 1 & & 1 & & & 62 \\
\hline Sor $\rightarrow$ Eve & 1 & 1 & & & & 124 \\
\hline
\end{tabular}

importance of tailoring the treatment of older patients based on comorbidities, suggests the use of sorafenib as frontline therapy (level of evidence $2 \mathrm{~B}$ ). Two randomized phase II studies were undertaken to evaluate the role of sorafenib in association with interferon- $\alpha$ and IL-2, respectively. Both trials failed to demonstrate an improvement in PFS from the combination of sorafenib plus cytokines compared with sorafenib alone [Jonasch et al. 2010; Procopio et al. 2011a].

\section{Sequential treatment}

The therapeutic approach based on sequential administration of different targeted agents has recently gained interest among physicians. In response to the previously unhoped-for results obtained with these new agents, which led to appreciable periods of disease control (PFS), investigators immediately looked forward to the possibility of further strengthening such results [Sonpavde et al. 2012]. Following the first observations showing that patients with $\mathrm{mRCC}$ with good or intermediate prognosis who were relapsing from sunitinib were able to respond to sorafenib or vice versa - thus pointing out a lack of cross resistance between these two most commonly administered drugs - a series of retrospective analyses and prospective investigations, most concerning sorafenib and sunitinib, have been carried out [Escudier et al. 2012] (level of evidence $2 \mathrm{~B}$ ). A retrospective analysis of a large cohort of patients having mRCC (333 cases treated with different sequences of therapies) identified the same OS independently of the sequences used (sunitinib followed by sorafenib or vice versa, or other targeted agents used sequentially) [Procopio et al. 2011b].

Retrospective evaluation of sequential treatment with sorafenib and sunitinib in different institutions (Table 2) seems to indicate that the sequence sorafenib to sunitinib is more beneficial in terms of PFS than sunitinib to sorafenib [Escudier et al. 2012]. A recent meta-analysis of available studies identified a global PFS benefit of 15.3 months for the sequence sorafenib to sunitinib, compared with 13.4 months for the sequence sunitinib to sorafenib $(p=0.006)$ [Liewen et al. 2012]. These findings are highly biased by an inadequate methodologic approach due to randomness in the allocation of both patients and sequences and therefore need to be confirmed through well designed randomized studies; however, a possible explanation could have as a reference point the preclinical investigation of Paez-Ribas [Paez-Ribas, 2009; Porta et al. 2010]. It is likely that more evidence about this matter will come from the ongoing phase III randomized crossover study (SWITCH trial) intentionally designed to identify the most appropriate treatment; the study compares the sequence sorafenib to sunitinib and vice versa [ClinicalTrials.gov identifier: NCT01481870]. Other information supporting the role of sequential treatment using tyrosine kinase inhibitors can be drawn from the registration phase III study (AXIS trial), in which patients with mRCC previously treated with cytokines or tyrosine kinase inhibitors have been randomly allocated to treatment with either axitinib or sorafenib, the latter taken as the reference drug [Rini et al. 2011a]. A significant improvement in median PFS was reported in the entire study population in favor of the axitinib arm versus the sorafenib arm (6.7 months compared with 4.7 months respectively; HR 0.665). The subgroup analysis carried out in each experimental group in patients previously treated with sunitinib showed less benefit in terms of PFS prolongation (4.8 months for patients treated with axitinib and 3.4 months for patients treated with sorafenib); in both cases, however, these benefits appear lower than the scan interval time of 8 weeks set in the study protocol [Rini et al. 2011a]. The final analysis of the AXIS study 
presented at the FDA approval meeting for axitinib did not show any difference in terms of OS in either experimental group (axitinib or sorafenib) for either the whole population accrued or the sunitinib-pretreated population [US Food and Drug Administration, 2011].

This finding seems to be in line with previous observations [Procopio et al. 2011b]. Although it is now clear that different drugs are able to induce different benefits in PFS, these different approaches do not seem to affect the final OS data. Therefore, despite the more or less consistent prolongation of global PFS achieved with the sequential use of targeted agents, data supplying convincing and definite answers concerning the impact of this advantage on patient OS are not yet available. Indeed, OS remains a fundamental discriminating factor in the value of sequential treatment; a prolongation of PFS that is restricted to a possible and temporary amelioration of a patient's quality of life is one thing, whereas the chance to add years to that life is quite another.

\section{Use of sorafenib in selected patient populations}

\section{Older patients}

According to epidemiologic data, the occurrence of renal cell carcinoma (RCC) is particularly high in patients older than 65 years, with an incidence diagnosis rate exceeding $25 \%$. The therapeutic approach for these patients calls for caution based on their general physical decline and frequent comorbid conditions [Dutcher et al. 2010]. Chiefly for regulatory reasons, most studies of the development of targeted agents for RCC have been undertaken in selected populations that seldom include older patients (Table 3 ). The experimental protocol of the randomized placebocontrolled pivotal phase III study (TARGET) with sorafenib did not include an age limit [Bellmunt et al. 2010a], however, so it has been possible to obtain preliminary information about the efficacy and safety of this agent in the older population. Of 903 patients randomized to receive either sorafenib or placebo, $13 \%$ were older than 70 years (two patients were 80 and 86 years old); among patients treated with sorafenib, efficacy in terms of both PFS and disease control was equal in older and younger patients (PFS 26.3 weeks compared with 23.9 weeks respectively, not significant; clinical benefit $84.3 \%$ compared with $83.5 \%$ respectively, not significant) [Eisen et al.
2008]. Similarly, no differences between older and younger patients have been recorded in regard to type and severity of adverse effects, which generally are grade $1-2$ severity and chiefly consist of diarrhea, alopecia, fatigue, anorexia, and skin reactions (level of evidence 2B) [Eisen et al. 2008]. This initial evidence has been subsequently substantiated in larger studies using sorafenib in conditions fully corresponding to everyday clinical practice, such as the European (EU-ARCCS) and American (NA-ARCCS) expanded-access studies, which accrued 1145 and 2504 patients respectively, and the PREDICT study. The subgroup analysis of older patients in the EU-ARCCS study found a PFS trend in favor of older patients compared with younger ones (8.2 months compared with 6.4 months respectively), with clinical benefit and toxicity rates fully superimposable between the two populations [Beck et al. 2011]. Similarly, in the NA-ARCCS study, the disease control rate and treatment safety observed in older patients were comparable to those of the whole population accrued [Stadler et al. 2010]. In contrast, preliminary data from the PREDICT study show a median PFS for older patients that is slightly lower than for the general population (6.1 and 7.8 months respectively), with a higher incidence of drugdose reductions [Jäger, 2012].

\section{Renal failure}

Age-related risk factors such as hypertension and diabetes, as well as situations that result from single or bilateral surgical intervention, are the main factors responsible for the onset of renal failure. The condition occurs in a considerable percentage of patients with renal carcinoma, particularly older patients [Parsa et al. 2009]. Altered renal function is difficult to overcome because most of the drugs used to treat it cannot be administered along with drugs to treat RCC, or their doses must be significantly reduced [Parsa et al. 2009]. Sorafenib may play a key role in the treatment of this patient population because of its metabolic pathway, which is predominantly hepatic; pharmacokinetic investigations show few changes in the drug profile in patients with renal impairment [Escudier, 2011]. Case studies and a retrospective survey have validated the pharmacokinetic data, confirming the potential use of sorafenib in patients with mild to moderate renal insufficiency and in whom dialysis is not a contraindication to therapy (level of evidence 3A) [Castagneto et al. 2011; Masini et al. 2012; Parsa et al. 2009; Ruppin 
Table 3. Despite the fact that older patients represent $25 \%$ of patients in clinical practice, this setting is not fully represented in clinical trials.

\begin{tabular}{|c|c|c|c|c|}
\hline & $N$ & $\begin{array}{l}\text { Median age, } \\
\text { years (range) }\end{array}$ & $\begin{array}{l}\text { Patients } \geq \\
65 \text { years, } \%\end{array}$ & $\begin{array}{l}\text { Patients } \geq \\
70 \text { years, \% }\end{array}$ \\
\hline $\begin{array}{l}\text { Sorafenib TARGET } \\
\text { Eisen et al. [2008] }\end{array}$ & 903 & $59(19-86)$ & 30 & 13 \\
\hline $\begin{array}{l}\text { Sorafenib NA-ARCCS } \\
\text { Bukowski et al. [2010], } \\
\text { Stadler et al. [2010] }\end{array}$ & 2504 & $63(13-93)$ & 45 & 29 \\
\hline $\begin{array}{l}\text { Sorafenib EU-ARCCS } \\
\text { Beck et al. [2011] }\end{array}$ & 1150 & $62(18-84)$ & 41 & 23 \\
\hline $\begin{array}{l}\text { Sunitinib phase III* } \\
\text { Motzer et al. [2007] }\end{array}$ & 750 & $62(27-87)$ & 37 & - \\
\hline $\begin{array}{l}\text { Sunitinib expanded access } \\
\text { programme } \\
\text { Gore et al. [2009] }\end{array}$ & 4371 & $59(19-89)$ & 32 & - \\
\hline $\begin{array}{l}\text { Pazopanib phase III* } \\
\text { Sternberg et al. [2010] }\end{array}$ & 435 & $59(28-85)$ & 35 & - \\
\hline Axitinib phase III & \multirow[t]{2}{*}{723} & Ax: $61(20-82)$ & - & - \\
\hline Rini et al. [2011a] & & Sor: $61(22-80)$ & - & - \\
\hline $\begin{array}{l}\text { Bevacizumab + IFN phase III* } \\
\text { Escudier et al. [2007b] }\end{array}$ & 649 & $61(30-82)$ & 37 & - \\
\hline $\begin{array}{l}\text { Bevacizumab + IFN phase III* } \\
\text { Rini et al. [2008] }\end{array}$ & 732 & $61(56-70)+$ & - & - \\
\hline $\begin{array}{l}\text { Temsirolimus phase III } \\
\text { Hudes et al. [2007] }\end{array}$ & 626 & $59(23-86)$ & 30 & - \\
\hline $\begin{array}{l}\text { Everolimus RECORD-1 phase III* } \\
\text { Osanto et al. [2010] }\end{array}$ & 416 & $61(27-85)$ & 37 & 18 \\
\hline $\begin{array}{l}\text { *Median age (range) shown only for } \\
\text { +Median (interquartile range). } \\
\text { EU-ARCCS, European Advanced Rer } \\
\text { Advanced Renal Cell Carcinoma Sor } \\
\text { Evaluation Trial. }\end{array}$ & $\begin{array}{l}\text { estigat } \\
\text { II Carci } \\
\text { Study }\end{array}$ & $\begin{array}{l}\text { reatment arm li.e. } \\
\text { Sorafenib Study; If } \\
\text { ET, Treatment App }\end{array}$ & $\begin{array}{l}\text { control arms). } \\
\text { eron; NA-ARCC } \\
\text { n Renal Cell Ca }\end{array}$ & $\begin{array}{l}\text { rth American } \\
\text { Global }\end{array}$ \\
\hline
\end{tabular}

et al. 2009; Shinsako et al. 2010]. However, in patients with altered renal function, careful selection and watchful monitoring to ensure that doses are adjusted at the right time are strongly recommended.

\section{Cardiac failure}

Several tyrosine kinase inhibitors carry an increased risk of cardiovascular adverse effects, including heart failure, myocardial ischemia, and hypertension, the latter being the most frequent [Cheng et al. 2011]. The summary of product characteristics for sorafenib (http://www.ema.europa.eu/docs/ en_gb/document_library/epar_product_information/human/000690/wc500027704.pdf) reports an onset of hypertension, generally mild to moderate and particularly occurring during the first weeks of treatment, which is usually easily controlled with standard antihypertensive therapy. Referring to the pivotal randomized placebo-controlled phase III study (TARGET), the summary of product characteristics for sorafenib also reports a slightly higher risk of ischemic heart disease and myocardial infarction in patients treated with sorafenib $(2.9 \%)$ compared with patients treated with placebo $(0.4 \%)$. Even though the sorafenib-induced risk of cardiac events appears lower and more manageable in comparison with competitors [Bellmunt et al. 2010a; Cheng et al. 2011; Escudier et al. 2012; Orphanos et al. 2009], ethical principles and precautionary measures call for careful consideration of patients, particularly those with preexisting risk. In addition, older patients with ejection fractions lower than $40 \%$ should be excluded because of elevated risk [Dutcher et al. 
Table 4. Key points and current scenario in renal cell carcinoma medical therapy based on expertise of our institution.

\begin{tabular}{l} 
Key issues \\
Analysis of the therapeutic scenario for $\mathrm{mRCC}$ is complicated by heterogeneity in both the disease and the \\
population enrolled in studies. \\
Seven targeted agents have been shown to improve the prognosis of advanced-stage mRCC. \\
No agent or therapeutic sequence has been observed to be superior to the others in extending survival. \\
Therefore, optimization of medical treatment tailored to patient characteristics and disease is strongly \\
recommended. \\
Both clinical studies and practice have validated the role of sorafenib in patients with mRCC in different \\
populations and lines of treatment. Thus, sorafenib is a good option because of its tolerability profile and \\
efficacy. \\
\hline mRCC, metasatic renal cell carcinoma.
\end{tabular}

2010]. Despite this situation, the same authors report that asymptomatic patients with ejection fractions between $40 \%$ and $50 \%$ could be treated with sorafenib if they have no other cardiovascular risk factors. The authors say that hypertension, including hypertension in older patients, is not necessarily a contraindication to sorafenib therapy [Dutcher et al. 2010].

The outcomes of a phase I trial with 53 patients with advanced malignancies and concomitant cardiovascular risks that was specifically designed to characterize and assess the safety of sorafenib [Tolcher et al. 2011] are worth mentioning. The main inclusion criteria were ejection fraction $45 \%$ or higher, QT interval corrected for heart rate (QTc) less than $500 \mathrm{~ms}$, and hypertension even controlled with medical therapy (systolic blood pressure $170 \mathrm{mmHg}$ or below, diastolic blood pressure $100 \mathrm{mmHg}$ or below). Cardiovascular safety was evaluated by QT/QTc modifications assessed by electrocardiography, changes of ejection fraction, blood pressure, and heart rate [Tolcher et al. 2011]. The results of the trial show that treatment with sorafenib in continuous dosing induced modest effects on cardiovascular parameters essentially without clinical significance. However, to be completely safe and to maximize the clinical benefit of sorafenib, the authors recommend the correct management of cardiac comorbidities, active surveillance, and timely measures in case of onset of cardiac toxicity signs [Tolcher et al. 2011]. It is extremely important to point out the reversibility of these adverse effects. Nevertheless, once a drug-related cardiotoxic event clears up, the balance between the expected benefits of the targeted therapy and the risk of onset of new events should be carefully assessed; subsequently, many patients may continue the treatment at lower doses without the risk of further cardiovascular damage.

\section{Conclusions}

The introduction of sorafenib into the medical treatment of mRCC represents a fundamental turning point (Table 4). Following the undeniable evidence supplied by the pivotal randomized phase III study that led to the acknowledgment and approval of the drug by the main international regulatory authorities, a series of enlarged and specific studies allowed better characterization and positioning of sorafenib in everyday medical practice, thus optimizing its use in different situations and patient populations. The scientific community can rely on several new targeted agents, all of which have remarkable and unquestionable attributes. Despite these advances, sorafenib represents a substantial reference point, particularly because of its safety profile that allows the maintenance of nearly steady drug-dose levels even in high-risk populations, thus positively affecting efficacy. The ability to treat patients with altered renal function or cardiovascular disturbances, as well as older patients with reduced organ function, cannot be undervalued. Low rates of dose reduction and treatment withdrawal are reported in the clinical investigations of sorafenib; a high level of compliance with treatment has also been observed with this drug, which can be considered the litmus paper of patient product acceptance. Emphasizing that adherence to the recommended dosage is fundamental to clinical success, Bellmunt and colleagues pointed out that the continuous-dosing schedule of sorafenib 
makes the drug easier to manage and offers more consistent control of patient care [Bellmunt et al. 2010a]. These characteristics, along with proved efficacy in frontline treatment and in patients relapsed after previous treatment with other targeted agents, make sorafenib a mainstay in the treatment of mRCC.

\section{Acknowledgements}

Editorial assistance for this manuscript was provided by Dragonfly Editorial.

\section{Funding}

Editorial assistance was funded by Bayer HealthCare.

\section{Conflict of interest statement}

Giuseppe Procopio receives honoraria as advisor or consultant from AVEO pharma, Bayer HealthCare, GSK, Pfizer, and Sanofi.

\section{References}

Aveo-Astellas (2011) Aveo and Astellas announce tivozanib successfully demonstrated progression-free survival superiority over sorafenib in patients with advanced renal cell cancer in phase 3 tivo- 1 trial. Available at: http://www.astellas.com/en/corporate/ news/detail/aveo-and-astellas-announce-tiv.html (accessed 9 May 2012).

Awada, A., Hendlisz, A., Christensen, O., Lathia, C., Bartholomeus, S., Lebrun, F. et al. (2012) Phase I trial to investigate the safety, pharmacokinetics and efficacy of sorafenib combined with docetaxel in patients with advanced refractory solid tumours. Eur $\mathcal{F}$ Cancer 48 : 465-474.

Beck, J., Procopio, G., Bajetta, E., Keilholz, U., Negrier, S., Szczylik, C. et al. (2011) Final results of the European Advanced Renal Cell Carcinoma Sorafenib (EU-ARCCS) expanded-access study: a large open-label study in diverse community settings. Ann Oncol 22: 1812-1823.

Bellmunt, J., Fishman, M., Eisen, T. and Quinn, D. (2010a) Expert opinion on the use of first-line sorafenib in selected metastatic renal cell carcinoma patients. Expert Rev Anticancer Ther 10: 825-835.

Bellmunt, J., Maroto-Rey, P., Trigo, J., Carles, J., Guillem, V., Lopez-Martin, J. et al. (2010b) A phase II trial of first-line sorafenib in patients with metastatic renal cell carcinoma unwilling to receive or with early intolerance to immunotherapy: SOGUG study 06-01. Clin Transl Oncol 12: 503-508.

Bellmunt, J., Negrier, S., Escudier, B., Awada, A. and Aapro, M. (2009) The medical treatment of metastatic renal cell cancer in the elderly: position paper of a SIOG taskforce. Crit Rev Oncol Hematol 69: 64-72.

Bukowski, R.M., Stadler, W.M., McDermott, W.F., Dutcher, J.P., Knox, J.J. Miller, W.H. et al. (2010) Safety and efficacy of sorafenib in elderly patients treated in the North American advanced renal cell carcinoma sorafenib expanded access program. Oncology 78: 340-347

Castagneto, B., Stevani, I., Giorcelli, L., Montefiore, F., Bigatti, G., Pisacco, P. et al. (2011) Sustained response following sorafenib therapy in an older adult patient with advanced renal cancer on hemodialysis: a case report. Med Oncol 28: 1384-1388.

Cheng, H., Kari, G., Dicker, A., Rodeck, U., Koch, W. and Force, T. (2011) A novel preclinical strategy for identifying cardiotoxic kinase inhibitors and mechanisms of cardiotoxicity. Circ Res 109: 1401-1409.

Clark, J., Eder, J., Ryan, D., Lathia, C. and Lenz, H. (2005) Safety and pharmacokinetics of the dual action Raf kinase and vascular endothelial growth factor receptor inhibitor, BAY 43-9006, in patients with advanced, refractory solid tumors. Clin Cancer Res 11: 5472-5480.

De Reijke, T., Bellmunt, J., Van Poppel, H., Marreaud, S. and Aapro, M. (2009) EORTC-GU group expert opinion on metastatic renal cell cancer. Eur f Cancer 45: 765-773.

Dutcher, J., Tannir, N., Bellmunt, J. and Escudier, B. (2010) Experience with sorafenib and the elderly patient. Med Oncol 27: 1359-1370.

Eisen, T., Oudard, S., Szczylik, C., Gravis, G., Heinzer, H., Middleton, R. et al. (2008) Sorafenib for older patients with renal cell carcinoma: subset analysis from a randomized trial. I Natl Cancer Inst 100: 1454-1463.

European Medicines Agency (2006) Sorafenib approval. Available at: http://www.ema.europa. eu/docs/en_gb/document_library/epar_product_ information/human/000690/wc500027704.pdf (accessed 9 May 2012)

Escudier, B. (2011) Sorafenib for the management of advanced renal cell carcinoma. Expert Rev Anticancer Ther 11: 825-836.

Escudier, B., Eisen, T., Stadler, W., Szczylik, C., Oudard, S., Siebels, M. et al. (2007a) Sorafenib in advanced clear-cell renal-cell carcinoma. $N$ Engl f Med 356: 125-134.

Escudier, B., Pluzanska, A., Koralewski, P., Ravaud, A., Bracarda, S., Szczylik, C. et al. (2007b)

Bevacizumab plus interferon alfa-2a for treatment of metastatic renal cell carcinoma: a randomised, double-blind phase III trial. Lancet 370(9605): 2103-2111. 
Escudier, B., Eisen, T., Stadler, W., Szczylik, C., Oudard, S., Staehler, M. et al. (2009a) Sorafenib for treatment of renal cell carcinoma: final efficacy and safety results of the phase III Treatment Approaches in Renal Cancer Global Evaluation Trial. $\mathcal{F}$ Clin Oncol 27: 3312-3318.

Escudier, B., Szczylik, C., Hutson, T., Demkow, T., Staehler, M., Rolland, F. et al. (2009b) Randomized phase II trial of first-line treatment with sorafenib versus interferon alfa-2a in patients with metastatic renal cell carcinoma. f Clin Oncol 27: 1280-1289.

Escudier, B., Szczylik, C., Porta, C. and Gore, M. (2012) Treatment selection in metastatic renal cell carcinoma: expert consensus. Nat Rev Clin Oncol 9: 327-337.

Gollob J.A., Wilhelm, S., Carter, C. and Kelley, S. (2006) Role of Raf Kinase in cancer: therapeutic potential of targeting the Raf/MEK/ERK signal transduction pathway. Semin Oncol 33: 392-406.

Gore, M.E., Szczylik, C., Porta, C., Bracarda, S., Bjarnason, G.A., Oudard, S. et al. (2009) Safety and efficacy of sunitinib for metastatic renal-cell carcinoma: an expanded-access trial. Lancet Oncol 10(8): 757-763.

Hudes, G., Carducci, M., Tomczak, P., Dutcher, J., Figlin, R., Kapoor, A. et al. (2007) Temsirolimus, interferon alfa, or both for advanced renal-cell carcinoma. N Engl f Med 356(22): 2271-2281.

Jäger, D. (2012) PREDICT (Patient Characteristics in Renal Cell Carcinoma and Daily Practice Treatment with Sorafenib) global non-interventional study: final report. In: 34 th ESMO and 15th ECCO Meeting, Stockholm, Sweden, 2012.

Jonasch, E., Corn, P., Pagliaro, L., Warneke, C., Johnson, M., Tamboli, P. et al. (2010) Upfront, randomized, phase 2 trial of sorafenib versus sorafenib and low-dose interferon alfa in patients with advanced renal cell carcinoma: clinical and biomarker analysis. Cancer 116: 57-65.

Kirchner, H., Strumberg, D., Bahl, A. and Overkamp, F. (2010) Patient-based strategy for systemic treatment of metastatic renal cell carcinoma. Expert Rev Anticancer Ther 10: 585-596.

Liewen, R., Haile, S., Siciliano, R., Cathomas, R., Rothermundt, C., Stoll, S. et al. (2012) A pooled analysis of sequential therapies with sorafenib and sunitinib in metastatic renal cell carcinoma. Oncology 82: 333-340.

Masini, C., Sabbatini, R., Porta, C., Procopio, G., Di Lorenzo, G., Onofri, A. et al. (2012) Use of tyrosine kinase inhibitors in patients with metastatic kidney cancer receiving haemodialysis: a retrospective Italian survey. BfU Int 24 February 2012 (Epub ahead of print). DOI: $10.1111 /$ j.1464-410X.2012.10946.x
Moore, M., Hirte, H., Siu, L., Oza, A., Hotte, S., Petrenciuc, O. et al. (2005) Phase I study to determine the safety and pharmacokinetics of the novel Raf kinase and VEGFR inhibitor BAY 43-9006, administered for 28 days on/7 days off in patients with advanced, refractory solid tumors. Ann Oncol 16: 1688-1694.

Motzer, R.J., Hutson, T.E., Tomczak, P., Michaelson, M.D., Bukowski, R.M., Rixe, O. et al. (2007) Sunitinib versus interferon alfa in metastatic renal-cell carcinoma. N Engl f Med 356(2): 115-124.

National Comprehensive Cancer Network. (2012) V 2 guidelines for management kidney tumor. Available at: http://www.nccn.org/professionals/physician_gls/pdf/ kidney.pdf (accessed 9 May 2012).

Orphanos, G., Ioannidis, G. and Ardavanis, A. (2009) Cardiotoxicity induced by tyrosine kinase inhibitors. Acta Oncol 48: 964-970.

Osanto, S., Hutson, T., Calvo, E., Escudier, B., Oudard, S., Porta, C. et al. (2010) Efficacy and safety of everolimus in elderly patients (pts) with metastatic renal cell carcinoma. $\mathcal{F}$ Clin Oncol 28(suppl. 15): abstract 4608.

Paez-Ribes, M., Allen, E., Hudock, J., Takeda, T., Okuyama, H., Vinals, F. et al. (2009) Antiangiogenic therapy elicits malignant progression of tumors to increased local invasion and distant metastasis. Cancer Cell 15: 220-231.

Parsa, V., Heilbrun, L., Smith, D., Sethi, A. and Vaishampayan, U. (2009) Safety and efficacy of sorafenib therapy in patients with metastatic kidney cancer with impaired renal function.

Clin Genitourin Cancer 7: E10-E15.

Porta, C., Paglino, C. and Imarisio, I. (2010)

Sequencing tyrosine kinase inhibitors or immediately switching to mTOR inhibitors in advanced kidney cancer: a critical review. Eur f Clin Med Oncol 12 March 2011 (Epub ahead of print).

Procopio, G., Verzoni, E., Bracarda, S., Ricci, S., Sacco, C., Ridolfi, L. et al. (2011a) Sorafenib with interleukin-2 vs sorafenib alone in metastatic renal cell carcinoma: the ROSORC trial. Br F Cancer 104: 1256-1261.

Procopio, G., Verzoni, E., Iacovelli, R., Guadalupi, V., Gelsomino, F. and Buzzoni, R. (2011b) Targeted therapies used sequentially in metastatic renal cell carcinoma: results of a large experience. Expert Rev Anticancer Ther 11: 1631-1640.

Ratain, M., Eisen, T., Stadler, W., Flaherty, K., Kaye, S., Rosner, G. et al. (2006) Phase II placebocontrolled randomized discontinuation trial of sorafenib in patients with metastatic renal cell carcinoma. F Clin Oncol 24: 2505-2512. 
Rini, B.I., Halabi, S., Rosenberg, J.E., Stadler, W.M., Vaena, D.A., Ou, S.S. et al. (2008) Bevacizumab plus interferon alfa compared with interferon alfa monotherapy in patients with metastatic renal cell carcinoma: CALGB 90206. F Clin Oncol 26(33): 5422-5428.

Rini, B., Escudier, B., Tomczak, P., Kaprin, A., Szczylik, C., Hutson, T. et al. (2011a) Comparative effectiveness of axitinib versus sorafenib in advanced renal cell carcinoma (AXIS): a randomised phase 3 trial. Lancet 378: 1931-1939.

Rini, B., Tannir, N., Koralewski, P., Tomczak, A., Deptala, K., Kracht, Y. et al. (2011b) AMG 386 in combination with sorafenib in patients (pts) with metastatic renal cell cancer (mRCC): a randomized, double-blind, placebo-controlled, phase II study. f Clin Oncol (Suppl. 7): abstract 309.

Ruppin, S., Protzel, C., Klebingat, K. and Hakenberg, O. (2009) Successful sorafenib treatment for metastatic renal cell carcinoma in a case with chronic renal failure. Eur Urol 55: 986-988; quiz 988.

Shinsako, K., Mizuno, T., TeRyarada, T., Watanabe, J., Kamba, T., Nakamura, E. et al. (2010) Tolerable sorafenib therapy for a renal cell carcinoma patient with hemodialysis: a case study. Int F Clin Oncol 15: 512-514.

Sonpavde, G., Choueiri, T., Escudier, B., Ficarra, V., Hutson, T., Mulders, P. et al. (2012) Sequencing of agents for metastatic renal cell carcinoma: can we customize therapy? Eur Urol 61: 307-316.

Stadler, W., Figlin, R., Mcdermott, D., Dutcher, J., Knox, J., Miller, W., Jr, et al. (2010) Safety and efficacy results of the advanced renal cell carcinoma sorafenib expanded access program in North America. Cancer 116: 1272-1280.

Sternberg, C.N., Szczylik, C., Lee, E., Salman, P.V., Mardiak, J., Davis, I.D. et al. (2010) A randomized, double-blind phase III study of pazopanib in treatment-naive and cytokine-pretreated patients with advanced renal cell carcinoma (RCC). $\mathcal{F}$ Clin Oncol 28(6): 1061-1068.
Strumberg, D., Richly, H., Hilger, R., Schleucher, N., Korfee, S., Tewes, M. et al. (2005) Phase I clinical and pharmacokinetic study of the novel Raf kinase and vascular endothelial growth factor receptor inhibitor BAY 43-9006 in patients with advanced refractory solid tumors. $\mathcal{F} \mathrm{Clin} \mathrm{Oncol}$ 23: 965-972.

Tolcher, A., Appleman, L., Shapiro, G., Mita, A., Cihon, F., Mazzu, A. et al. (2011) A phase I openlabel study evaluating the cardiovascular safety of sorafenib in patients with advanced cancer. Cancer Chemother Pharmacol 67: 751-764.

US Food and Drug Administration (2007) Sorafenib FDA approval. Available at: http://www.cancer.gov/ cancertopics/druginfo/fda-sorafenib-tosylate (accessed 9 May 2012).

US Food and Drug Administration (2011) Oncologic Drugs Advisory Committee Meeting. NDA 202324.

Available at: http://www.fda.gov/downloads/ advisorycommittees/committeesmeetingmaterials/ drugs/oncologicdrugsadvisorycommittee/ ucm282290.pdf and http://www.fda.gov/downloads/ advisorycommittees/committeesmeetingmaterials/ drugs/oncologicdrugsadvisorycommittee/ucm 283657. pdf (accessed 9 May 2012)

Wilhelm, S., Adnane, L., Newell, P., Villanueva, A., Llovet, J. and Lynch, M. (2008) Preclinical overview of sorafenib, a multikinase inhibitor that targets both Raf and VEGF and PDGF receptor tyrosine kinase signaling. Mol Cancer Ther 7: 3129-3140.

Wilhelm, S., Carter, C., Lynch, M., Lowinger, T., Dumas, J., Smith, R. et al. (2006) Discovery and development of sorafenib: a multikinase inhibitor for treating cancer. Nat Rev Drug Discov 5: $835-844$.

Zustovich, F., Lombardi, G., Nicoletto, O. and Pastorelli, D. (2011) Second-line therapy for refractory renal-cell carcinoma. Crit Rev Oncol Hematol 83: 112-122.
Visit SAGE journals online http://tau.sagepub.com

@SAGE journals 